\title{
On Fast Transition between Shelters and Housing after Natural Disasters in Developing Regions
}

\author{
Gary S. Prinz ${ }^{1}$, Alain Nussbaumer ${ }^{1}$ \\ ${ }^{1}$ Ecole Polytechnique Fédérale de Lausanne, Lausanne, Switzerland \\ Presenting author's email address: gary.prinz@epfl.ch \\ Abstract Record Number: \\ Presentation Theme: Theme 2
}

Key Words: fast rebuilding, local fabrication, urban environments, natural disasters

\section{Brief biography of presenting author:}

Dr. Gary Prinz is a postdoctoral researcher in the Steel Structures Laboratory (ICOM) at the Ecole Polytechnique Fédérale de Lausanne (EPFL). He earned his PhD in civil engineering from Brigham Young University, where he worked on eccentrically braced frame seismic systems. Prior to joining the EPFL Dr. Prinz worked for a brief period as a blast engineering consultant at Applied Research Associates, Inc., where he helped design United States embassies and Federal Buildings.

\begin{abstract}
:
This paper presents the findings from an international workshop that brought together various NGOs, rebuilding coordinators, private sector leaders, engineers, and academics to discuss methods and issues related to fast reconstruction in developing regions affected by natural disasters. Natural disasters in developing regions often destroy homes and, together with economic conditions, force people to live in temporary shelters such as tents. Experience shows that rebuilding is often a long process because of issues related to land rights, evacuation of debris, standing building safety, coordination between local authorities, government organizations and NGO's, etc. In order to debate on the matter, the following themes were selected for the workshop:

- Stimulating local economies, involving the local unskilled workforce

- Meeting basic needs, fast and safe rebuilding with appropriate materials; particularly considering the use of steel as a building material.

- Adaptable construction, ways between affordable transitional shelters and sustainable long-term housing.

Discussions on these three themes led to consider the particular problematic of rebuilding in urban settings. Fast rebuilding technologies suitable for high density urban environments are needed, as well as strategies for implementing such technologies in environments where construction methods are tied to habit. In this context, the idea of promoting a multi-story, multifamily, locally fabricated shelter concept for fast rebuilding in urban environments is explained.
\end{abstract}

\section{Introduction:}

Natural disasters in developing regions often destroy homes and along with economic conditions force people to live in temporary shelters. After the 2010 magnitude Mw7.0 earthquake in Haiti, over 1.2 million Haitians were displaced from their homes, many seeking shelter in make-shift tents or "shanties" (Margesson and Taft-Morales, 2010). During that same year, massive flooding in Pakistan covered one-fifth of the country, affecting over 20 million people and forcing millions into temporary shelters (Guha-Sapir et al., 2011). In 2004, a magnitude Mw9.0 earthquake and subsequent tsunami devastated the west coast of Sumatra, Indonesia, displacing over 500,000 people from their homes (Meisl et al., 2006). With the relative frequency of natural disasters and the massive number of affected persons, strategies for fast reconstruction of shelters on a massive scale need to be developed: 1) to prevent relief organizations and governments from becoming overwhelmed as disasters reoccur during a project timeline, and 2) to quickly restore livelihood of the affected population.

When disaster situations affect developing countries, such as the Haiti earthquake, Pakistan floods, and Sumatra tsunami, the current status-quo for shelter relief is to import pre-assembled tents or tarp materials to accommodate immediate shelter needs. Following this emergency phase, organizations often construct individual "transitional shelters" aiming to restore livelihood and provide a shelter which has the potential to evolve into permanent housing. This typically involves providing a structural frame and basic covering (plastic tarp, etc.) that the 
individual owners then work to improve over time, transitioning into permanent housing. Due to issues related to land-rights, rubble removal, and coordination between local, governmental (GOs) and non-governmental organizations (NGOs), transition between temporary/evolving shelter and permanent housing is often a long process taking several years (Shelter Centre, 2011). Figure 1 illustrates the fabrication, storage, transport, and distribution scheme for emergency shelters commonly used in disaster situations. From Figure 1, supplying emergency shelter aid involves storage and transport of many large preassembled products which, depending on the proximity between the country supplying aid and the country receiving aid, could involve long distances. Figure 2 illustrates a typical evolution between shelter and permanent housing, based on the transitional approach proposed in the Transitional Shelter Guidelines (Shelter Centre, 2011). This shelter process is often not necessary in developed countries (see cases from the Japan, Chile, and New Zealand earthquakes) where sufficient infrastructure is already available to aid the displaced population during rebuilding.

Rebuilding efforts in densely populated urban environments pose particular issues, one of which is land overcrowding from the displaced population (Rencoret et al., 2010). Rebuilding in densely populated environments requires significant pre-planning at the government and local level prior to reconstruction, including preparation of utility lines, and services. Initial emergency relief efforts in the densely populated city of Port-auPrince following the 2010 Haiti earthquake created refugee-like camps, providing tarp and tent-like structures to meet temporary shelter needs; however, more than two years later, rebuilding efforts are still underway with many Haitians still displaced and living in a 'temporary' shelter situation (Booth, 2012). Figure 3 shows a "tent city" camp in Haiti following the 2010 disaster (US DOD, 2012).

Rebuilding efforts that span several years affect both the life and live-livelihood of the displaced population and can exacerbate often poor economic conditions. Additionally, corruption during construction and during governmental processes can affect shelter quality and inhabitant quality of life. Solutions that facilitate fast rebuilding, stimulate the local economy, and eliminate avenues for corruption are needed.

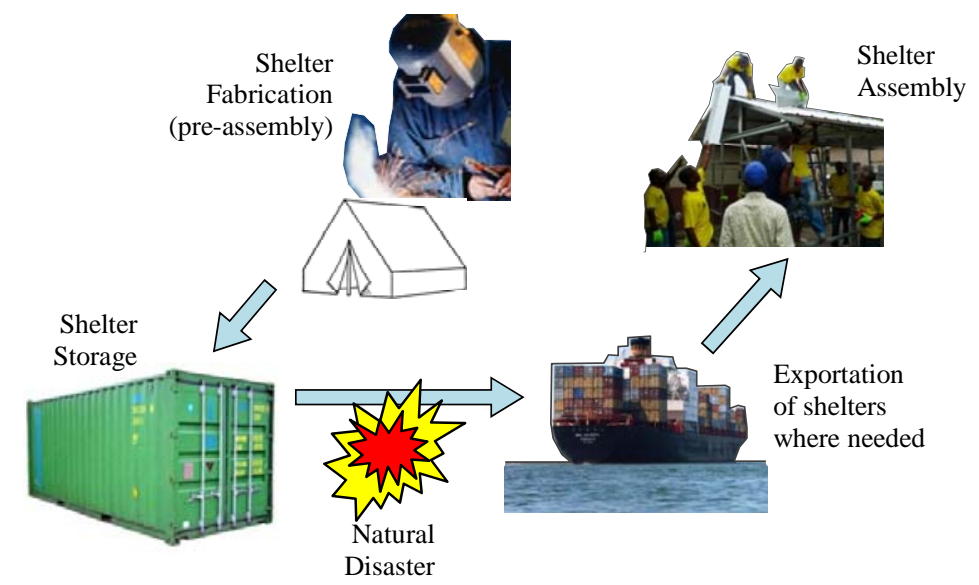

Figure 1. Typical emergency shelter scheme.

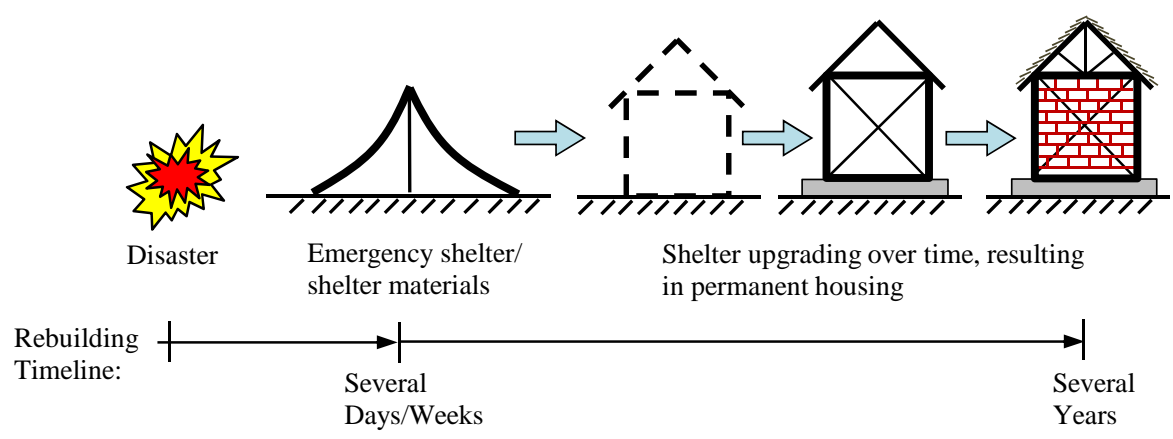

Figure 2. Typical transition to permanent housing following disaster.

To develop ideas related to fast rebuilding and to discover further reconstruction issues, an international workshop was organized in September 2011, bringing together key players in the rebuilding process. Participants in the workshop originated from all over the world, including: Haiti, South Africa, Brazil, Columbia, India, the United 
States, and Switzerland. The workshop was organized by the Steel Structures Laboratory (ICOM) at the Ecole Polytechnique Fédérale de Lausanne (EPFL), envisioning steel as an interesting material for fast rebuilding. This paper presents the key findings from the workshop and expands upon presented ideas to develop strategies for fast rebuilding. The paper begins with a brief overview of the workshop participants, followed by the key findings from discussions on fast transitions between shelters and permanent housing. Next, particular issues related to rebuilding in urban environments are discussed and a multi-purpose, multi-story, multi-family shelter concept is presented. Lastly, conclusions are provided.

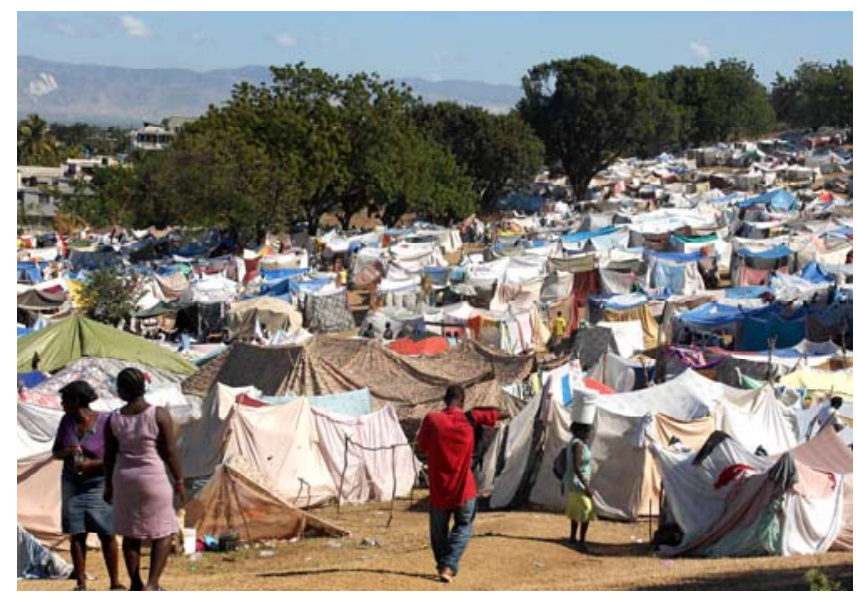

Figure 3. Port-au-Prince, Haiti, “tent city” following the 2010 earthquake (US DOD, 2012).

\section{Overview of Fast Rebuilding Workshop:}

The workshop brought together multiple sectors having various interests and experience in reconstruction, including: private sector leaders, NGOs, academics, engineers, and rebuilding coordinators, to discuss methods and issues related to fast reconstruction in developing regions affected by natural disasters. Around 20 people attended the different sessions of the workshop. To stimulate debate, the following themes were selected for discussion:

- Stimulating local economies, involving the local unskilled workforce

- Meeting basic needs, fast and safe rebuilding with appropriate materials; particularly considering the use of steel as a building material.

- Adaptable construction, ways between affordable transitional shelters and sustainable long-term housing.

Table 1 presents a list of participating organizations and the following paragraphs present of summary of the key findings from the workshop presentations and discussions.

Table 1 : Fast Rebuilding Workshop Participating Organizations

\begin{aligned} \hline Participating Organizations & Industry \\ Shelter Centre: & NGO \\ MEDAIR: & NGO \\ Project 16/6 Haiti: & Government (Haiti) \\ Swiss Humanitarian Aid Unit: & Government (Swiss) \\ InterTronco, SA: & Private Industry \\ Various: & Engineers/Architects \\ Indian Institute of Technology, Gandhinagar & Academic/Research \\ University of Stellenbosch: & Academic/Research \\ Universidade do Estado do Rio de Janeiro & Academic/Research \\ Institute of Construction and Infrastructure & Academic/Research \\ Management, ETHZ: & \\ Steel Structures Laboratory, EPFL: & Academic/Research \end{aligned}


Key findings:

1) Housing reconstruction must be resistant to future disasters and engage the local workforce. Between 2000 and 2009, 79\% of disaster casualties resulted from earthquakes and storms (EM-DAT, 2010). Precautions must be taken in the rebuilding process to protect shelters against these recurring events. These precautions must be understood during the construction process and be implemented at the grassroots level by individual owners (they will ultimately be responsible for sustaining and repairing the shelters). The individual owners must understand that little details can make the difference between a resistant and non-resistant structure (i.e. connection ties, bracing types, etc.). The overall consensus during the workshop indicated that shelter systems must engage the local work force during construction, through training and skill building. Mr. Clement Belizaire, project coordinator for the 16/6 project in Haiti and participant in the workshop, emphasized that every Haitian man is potentially a mason, capable of contributing to the reconstruction effort. It was agreed that coordination with locals and local involvement during rebuilding can boost morale and improve quality of life. However, one drawback to implementing local unskilled labor is the time required for training and skill building. This goes somewhat against a fast rebuilding concept and puts more emphasis on the transitional shelter necessities (training people to evolve their own shelters). The definition of a transitional shelter and its functional lifetime was found to be an open debate between the NGOs.

2) Sustainable shelter solutions shall respect local construction methods and materials. It was an overwhelming feeling from the NGOs with extensive field experience, that introduction of new technologies as a means of permanent housing will ultimately result in abandonment of the shelter for more traditional construction methods. Inhabitants unfamiliar with the building technology will be unable to repair, modify, or enhance their shelter, and ultimately convert back to familiar practices. As a result, reconstruction efforts aimed at providing individual housing units must include the local inhabitants and consider local traditions in the decision making process. It was discussed that implementation strategies for new technologies must begin at the grass-roots level, forming confidence and familiarity in the systems. This however takes significant time, again going against a fast rebuilding concept; however, one potential way to quickly introduce new technologies is through implementation of the technology into public buildings rather than individual houses (make the technology visible in everyday public life and let it trickle into private life and private dwellings).

3) Scientific tools such as life-cycle assessment (LCA) analysis can aid NGO's and relief organizations in determining suitable materials and technologies for affected regions. Recent LCA research by Wallbaum et al. (2012) investigated the sustainability of various construction technologies and materials currently used in individual housing construction. Figure 4 demonstrates a sample LCA ranking of sustainable building technologies (Wallbaum et al., 2012). From Figure 4, steel does not rank very well among other bio-based materials for use in individual housing. The various NGO's attending the FAST Rebuilding workshop showed interest in the LCA method and emphasized the need for such tools addressing shelter construction technologies to aid in decision making and provide justification for a chosen reconstruction path.

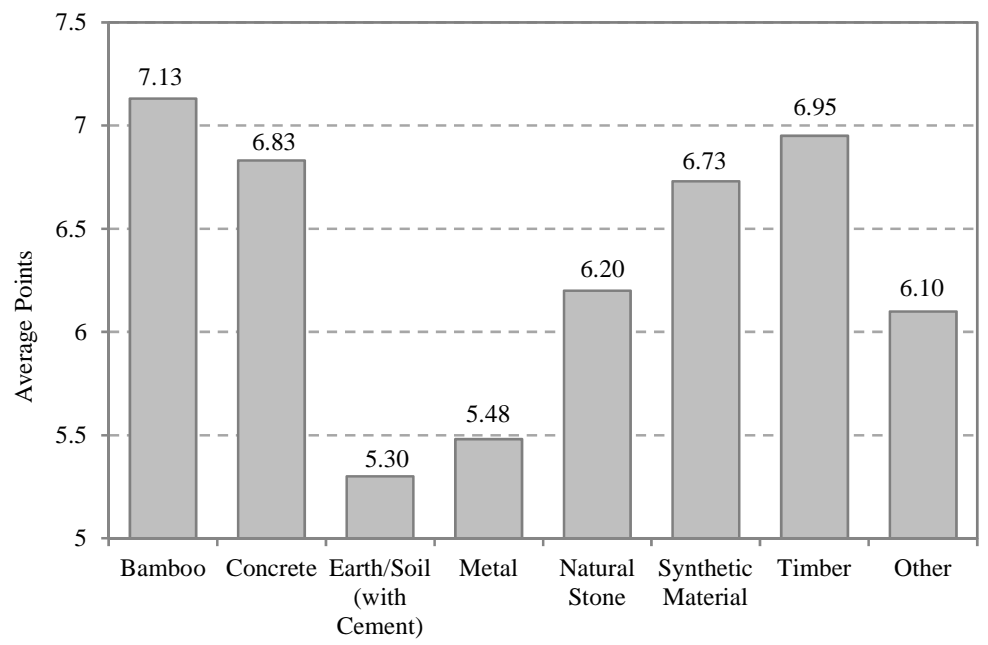

Figure 4. Example LCA results per construction category (Wallbaum et al., 2012). 
4) Fast rebuilding at the individual house level may not be the most sustainable solution. With issues regarding connection/organization of services and utilities, land use, transportation routes, shelter quality control, etc., quickly assembling semi-permanent shelters may complicate future efforts to install services. Discussion from the NGOs and government leaders with experience in recovery efforts emphasized the need for quickly assembled, self-erecting (no cranes), disaster resistant, multi-story buildings (2-4 story). Such buildings could function as emergency shelters, they use less land, directly following the disaster, and transition (with or without relocation) into schools or office buildings once reconstruction efforts have progressed. In this respect, steel could be a good material, even if it is not locally produced, to be used in combination with other local materials (bamboo, concrete, etc.). Steel properties are advantageous for large construction and earthquake resistance, having both high strength and ductility. It was also emphasized that while introducing new technologies is difficult at the individual home level (people often feel comfortable with traditional techniques), multi-story shelters that transition into schools once rebuilding progresses could be the best way to introduce new building technologies to developing communities.

5) Discussions with the NGOs and humanitarian aid organizations noted that rural strategies often fail in an urban environment, and indicated a need for new urban methods.

\section{Particular Problematic of Urban Settings:}

Reconstruction in urban settings poses particular challenges due to population density, building congestion, and integrated utilities and services (Rencoret et al., 2010). Individual single-story, single-family transitional shelters are well suited for rural environments having abundant space; however in urban environments with a dense population of displaced persons and limited space, individual family shelters are impractical and can overcrowd land area slowing down the reconstruction effort. Unfortunately, currently used shelter systems are often limited to a single story, requiring large land area to accommodate a large population. Additionally, restoring services, such as access to clean water and sanitation in densely populated areas requires land availability. During the early stages of disaster relief, land area must also be available for clearing of debris (often large quantities of debris from congested building environments). Following the 2010 Haiti earthquake, unofficial settlements, "tent cities", filled the open land space within Port-au-Prince complicating transportation and rubble removal efforts. Figure 5 shows the vast quantities of debris from the destroyed urban environment of Port-au-Prince, Haiti, and illustrates the complexity of rebuilding in an urban setting (IFRC, 2012).
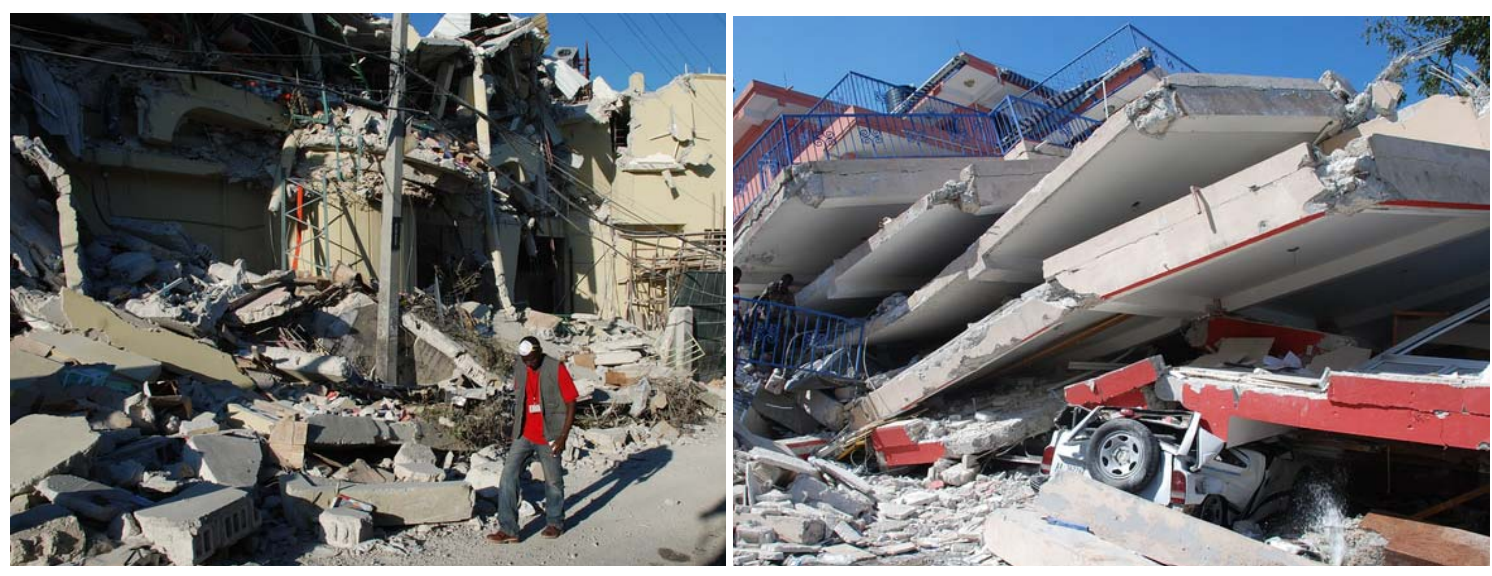

Figure 5. Urban destruction following 2010 Haiti Earthquake (IFRC, 2012)

\section{Multi-Story, Multi-Purpose, Multi-Family Transitional Shelters:}

In the context of an urban setting, it seems practical to develop multi-story (2-4 story) transitional shelters that accommodate multiple-families and free-up land for rebuilding of services, utilities, and clearing of damaged infrastructure. The multi-story shelters could initially serve as emergency shelter and slowly transition to function as public buildings (schools for example) once rebuilding has progressed. There also exists the possibility to upgrade the shelters into permanent apartments, or dismantle them if no longer needed. This concept could help to solve the issue of land rights, which commonly slows down rebuilding efforts, as the structure may ultimately belong to the community or government. A multi-story shelter, in which multiple families are housed in a single structure, require a multi-disciplinary approach between construction coordinators and water, sanitation, and 
hygiene programs (WASH for example) during the construction process. With WASH, multi-story, multi-family, shelters may improve efficiency, as only one person per building could be required to maintain the sanitation, water, and hygiene systems for all occupants. Additionally, the direct involvement from government decision makers and local community leaders would be encouraged as the constructed structures are intended to transition into government or community buildings.

Based on discussion between the FAST Rebuilding workshop participants, shelter systems using locally produced structural elements are desired over systems using imported structural elements. Using locally produced elements in the multi-story shelter design could: 1) engage local manufacturing and local workforce in the reconstruction effort helping to stimulate the local economy, 2) reduce construction time leading to faster rebuilding, and 3) could provide avenues for integrating new technologies into regions where traditional, inadequate, building methods dominate.

A promising solution for locally constructing multi-story shelters is to use multi-purpose structural elements along with special end connectors. A multi-purpose structural element is one that is currently locally produced for an application non-related to the shelter construction, but whose mechanical properties are well suited for carrying structural loads. In general, the multi-purpose shelter elements must be low-cost, light weight, quickly and easily fabricated at an industrial scale, durable, and have good structural properties to allow construction of multiple stories. Example multi-purpose elements include: steel angles, channel sections, cables, or light-gauge steel tubing (from ventilation ducts, sign posts, or used drill-piping), often found in developing regions. Used in combination with stored special end connectors, such elements could be used to erect large structural systems without the need for fasteners or cranes. Many existing scaffolding systems use this same concept. Figure 6 illustrates the multistory, multi-purpose, multi-family shelter concept and Figure 7 shows two sample multi-purpose element structure configurations.

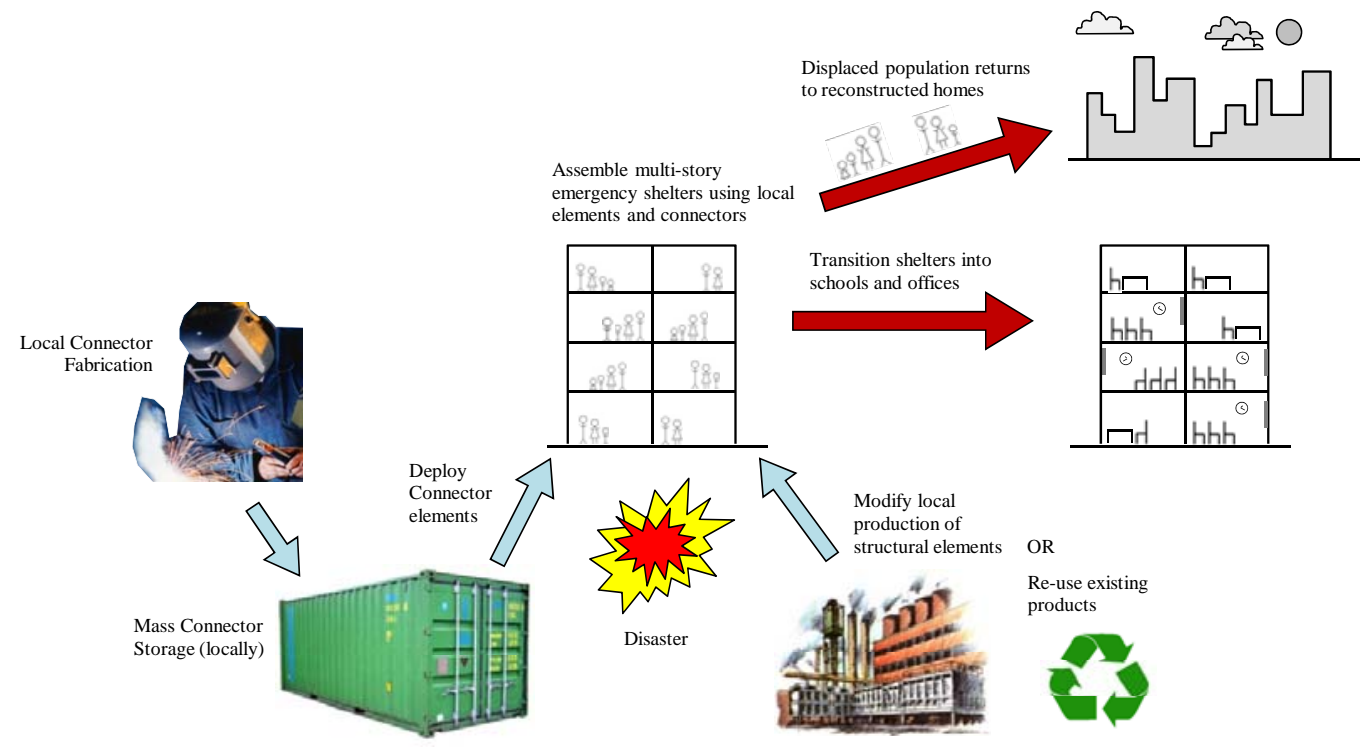

Figure 6. Multi-purpose, multi-story, multi-family, shelter concept.

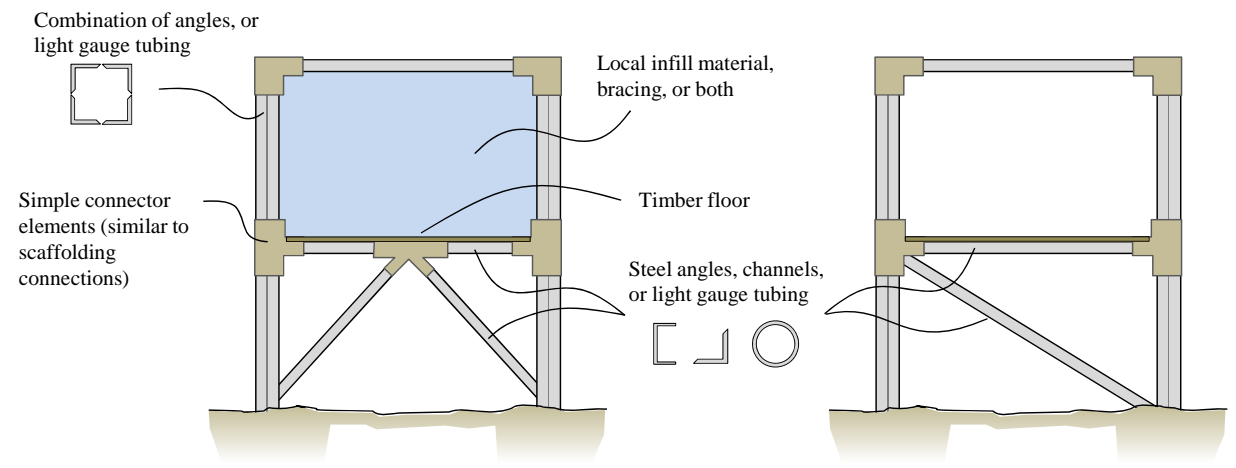

Figure 7. Example multi-purpose element shelter configurations. 


\section{Summary and Conclusions:}

This paper presents the findings from an international workshop on fast rebuilding which brought together leaders in the field of reconstruction following disasters. The workshop prompted particular focus on the problem of reconstruction in densely populated urban environments. The workshop inspired ideas related to local fabrication of multi-story shelters which were presented. The following are conclusions from the international workshop on fast rebuilding:

1. Housing reconstruction must be resistant to future disasters and engage the local workforce. Natural disasters (especially weather related ones) are usually recurring events and reconstruction must ensure improvement of performance/resistance.

2. Sustainable shelter solutions will respect local construction methods and materials. Ultimately local inhabitants will adapt, repair, and improve their shelter and unfamiliar construction techniques will result in abandonment of the shelter for more traditional construction.

3. Existing research tools, such as life-cycle assessment, may be useful to relief organizations in helping to determine suitable construction approaches.

4. A multi-story shelter concept to house multiple families may be a better approach in urban environments, and using locally produced materials and no fasteners or complicated assemblage in such structures may help to: 1) stimulate local economies (by engaging the local workforce and industry), 2) allow much needed space for reconstruction of damaged structures and utilities, and 3) provide an avenue for introducing new technologies (by using the multi-story shelters as public buildings following their emergency function).

\section{References:}

Booth, W. (2012). "Two years after quake, signs of progress in Haiti." The Washington Post: Retrieved February 13, 2012, from http://www.washingtonpost.com/world/americas/two-years-later-signs-of-progress-inhaiti/2012/2001/2011/gIQA2009aSrP_story.html.

EM-DAT (2010). "The OFDA/CRED International Disaster Database." Universite Catholique de Louvain: Brussels, Belgium.

Guha-Sapir, D., Vos, F., Below, R., with Ponserre, S. (2011). "Annual disaster statistical review 2010: the numbers and trends." Centre for Research on the Epidemiology of Disasters (CRED): Brussels, Belgium.

IFRC (2012). "Haiti earthquake - search and rescue." International Federation of Red Cross and Red Crescent Societies (IFRC): Retrieved February 13, 2012, from http://www.ifrc.org/en/news-and-media/photogalleries/2010.

Margesson, R. a. T.-M., M. (2010). "Haiti Earthquake: Crisis and Response." Congressional Research Service: Library of Congress, 101 Independence Ave, Washington, D.C.

Meisl, C. S., Safaie, S., Elwood, K.J., Gupta, R., and Kowsari, R. (2006). "Housing reconstruction in Northern Sumatra after the December 2004 great Sumatra earthquake and tsunami." Earthquake Spectra, 22(S3): S777-S802.

Rencoret, N., Stoddard, A., Haver, K., Taylor, G., and Harvey, P. (2010). "Haiti earthquake response - context analysis." Active Learning Network fo Accountability and Performance in Humanitarian Action (ALNAP).

Shelter Centre (2011). "Transitional shelter guidelines." http://sheltercentre.org.

US DOD (2012). "A camp for thousands." U.S. Department of Defense, Lead Photos: January 2010 Archive: Retrieved February 12, 2012, from http://www.defense.gov/homepagephotos/.

Wallbaum, H., Ostermeyer, Y., Salzer, C., and Escamilla, E.Z. (2012). "Indicator based sustainability assessment tool for affordable housing construction technologies." Ecological Indicators, 18(2012): 353-364. 